\title{
A chain is only as strong as its weakest link
}

\author{
Patrick M. McCarthy, MD
}

\footnotetext{
From the Bluhm Cardiovascular Institute and Division of Cardiac Surgery, Northwestern University Feinberg School of Medicine, Chicago, Ill.

Disclosures: P.M. is a consultant for and receives royalties from Edwards Lifesciences and is a consultant for Abbott Vascular.

Received for publication March 21, 2016; accepted for publication March 24, 2016; available ahead of print April 27, 2016.

Address for reprints: Patrick M. McCarthy, MD, Northwestern University Feinberg School of Medicine, 201 East Huron St, Suite 11-140, Chicago, IL 60611-2908 (E-mail: pmecart@nmh.org).

J Thorac Cardiovasc Surg 2016;152:e19-20

0022-5223/\$36.00

Copyright (C) 2016 by The American Association for Thoracic Surgery

http://dx.doi.org/10.1016/j.jtcvs.2016.03.053
}

A single stitch can make a big difference in the complex world of heart valve surgery. I first learned this lesson in the late 1980s as a fellow at the Mayo Clinic, when we had to reoperate weeks after aortic valve replacement when a single suture had pulled through the tissue, creating a perivalve leak, hemolysis, and heart failure. The lesson from that experience stuck with me. I was fortunate that I learned it so early, and with my trainees I have always focused on minimizing the risk of perivalve leak. ${ }^{1}$

We wear our magnifying loupes because we need to be very precise. An error of $1 \mathrm{~mm}$ in a coronary bypass distal anastomosis can lead to myocardial infarction or even death. Precision is important in mitral valve surgery as well. Repair sutures can be placed too close to the leaflet, leading to leaflet perforation with secondary hemolysis. Sutures can be placed too far away from the annulus or too deep in the tissue, causing injury to the circumflex coronary artery. Sutures can be placed too superficially and may pull through the tissue, and the repair ring or valve prosthesis may dehisce. Local factors, such as the degree of fibrosis of the mitral annulus, calcification, infection, and tissue quality (possibly impaired by steroids or immunosuppressive medications), also can lead to failure of valve repair or replacement. When we began downsizing rings for functional mitral regurgitation, ring dehiscence was not uncommon and was one of the causes of recurrent mitral regurgitation in that particular pathophysiological condition. All of the aforementioned factors can contribute to the important clinical problem of recurrent mitral regurgitation.

Intuitively, it makes sense that a dehisced suture could redistribute tension to the adjacent sutures or, analogously, that ruptured chords on a posterior mitral leaflet could redistribute tension to the adjacent nonruptured mitral valve chords. Although this seems obvious, how can it be proven? To my knowledge, it had never been demonstrated until this work by Pierce and colleagues in a collaboration between the University of Pennsylvania and Georgia Institute of Technology. ${ }^{3}$ The authors report an ovine model that they developed to study the impact of ring size, shape, and other

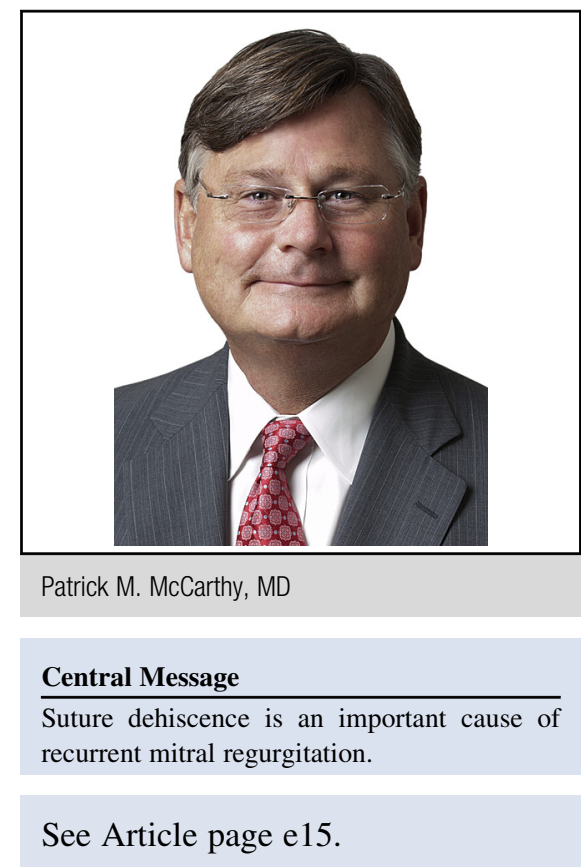

factors that can impact suture forces. They have developed novel transducers that can allow quantification of individual suture tension after mitral annuloplasty. ${ }^{4}$

Using the elegant data and graphs that we have come to expect from these investigators, they were able to clearly demonstrate suture dehiscence. The animal was given a bolus of epinephrine to increase contractility force on the sutures. As the left ventricular pressure rose to $188 \mathrm{~mm}$ $\mathrm{Hg}, 1$ anterior suture experienced twice the force load of other sutures, rising to $16.7 \mathrm{~N}$, then suddenly dropping to $0.6 \mathrm{~N}$ as the suture tore through the tissue. (The knot was intact at autopsy.) Simultaneously, the 2 adjacent sutures experienced a sudden increase in force. Thus, the dehisced suture began a cascade of increased suture force that could have led to dehiscence of other sutures, and led to recurrent mitral regurgitation in a clinical situation. Only by serendipity were they able to capture that event and confirm what we intuitively had expected. Clinically, I have noted single suture dehiscence, but more commonly I see 2 or 3 adjacent sutures. In addition, Pierce and colleagues point out the importance of careful perioperative blood pressure control. In my career, I have seen dehiscence associated with early unusual hypertension.

I never expected to write an editorial about a case report, let alone a case report from a single ovine experiment. But this is a unique accidental finding that has a clear clinical message, especially for those in training or early in their 
careers, and for those of us involved in training. The old adage that a chain is only as strong as its weakest link seems apt for our surgical endeavors.

\section{References}

1. Duncan BF, McCarthy PM, Kruse J, Andrei AC, Li Z, Russell HM, et al. Paravalvular regurgitation after conventional aortic and mitral valve replacement: a benchmark for alternative approaches. J Thorac Cardiovasc Surg. 2015;150:860-8.
2. Gillinov AM, Cosgrove DM, Lytle BW, Taylor PC, Stewart RW, McCarthy PM, et al. Reoperation for a failure of mitral valve repair. J Thorac Cardiovasc Surg. 1997; 113:467-75.

3. Pierce EL, Gentile J, Siefert AW, Gorman RC, Gorman JH, Yoganathan AP. Realtime recording of annuloplasty suture dehiscence reveals potential mechanism for dehiscence cascade. J Thorac Cardiovasc Surg. 2016;152:e15-7.

4. Seifert AW, Pierce EL, Lee M, Jensen MØ, Aoki C, Takebayashi S, et al. Suture forces in undersized mitral annuloplasty: novel device and measurements. Ann Thorac Surg. 2014;98:305-9. 